\title{
The significance of the reform of the teaching and scientific research of engineering management professional by integration thinking theory
}

\author{
Yanqun -Tang ${ }^{1}$, Zhaohui- Wang ${ }^{1}$ \\ ${ }^{1}$ College of Civil Engineering \& Mechanics, Central South University of Forestry \& Technology \\ Changsha, China \\ E-mail: tangyanzi2009@163.com
}

\begin{abstract}
This paper first introduced the integrated thinking simple: Integrative thinking is a kind of creative thinking, which involves two kinds of contradictory ideas in the mind, and from which the optimum solution is deduced. Then it illustrates its significant roles in the teaching and research of engineering management professional in the higher education in China.
\end{abstract}

Keywords-integrated thinking, project management professional, scientific research, teaching reform

\section{PREFACE}

Integrative thinking is a kind of creative thinking[1], which involves two kinds of contradictory ideas in the mind, and from which the optimum solution is deduced. When we face with conflict, even opposite scheme, we are satisfied with the existing scheme alternative way of different thinking by traditional thinking; but the integration thinking is find creative solutions by exploring the deeper insight into factors, which draw the outline of variable nonlinear relation between the problem as a whole in the big background consideration, and eliminate the conflict between different views. Integrated thinking also deal with two opposing points of view, and in the comprehensive advantages of the parties in the process of breakthroughs, its core is a positive attitude (position) to seek better solutions. This is a kind of "thinking habit"[2、3], all the people can cultivate and train consciously you to explore the ability of creative solutions[4]. ROM. Each school of management successful teaching experience shows that, the integration of thinking ability can be trained; students can proficiency in command of this method and more confident and successful. Therefore, the integration thinking has important significance on our teaching and scientific research.

\section{II .THE TEACHING WORK}

Aiming at the engineering management specialty in the current teaching mode existing problems, integrated thinking education significance mainly reflects in the following aspects[5]:

A. the teaching idea

The teaching mode from theory to practice, which is objectivism long pursued in our project management professional. The great objective tendency restricted the people subjective activity in a certain extent. Integrated thinking belongs to constructivism teaching concept, which embodied in uncomment with our present solutions to the existing schemes and reflection, question or even criticize. Modeling is an important method to integrate thinking, through the modeling problem, we can be the logical and clear causal relationship, and definite the problems clearly, so as we are able to solve the problem by adopting appropriate methods.

\section{$B$. the target inclination}

We are focuses on learners low order ability training on the specialty of engineering management mode, and the serious lag in time to the requirements of the learners. Low order ability is refers to the use of low order to think complete memory task, and solve the psychological characteristics of well-structured problems; The higher order ability base on higher-order thinking ,which to solve the carrier structure problems or complicated task of psychological characteristics. Project management is becoming more and more professional mode reform to cultivate learners' high order ability as the goal

orientation, the emphasis is the social development and technological progress of a kind of inevitable. Generally speaking, students can be well solved the well-structured problems, but they lack of the ability to solve problem of carrier structure. Integrated thinking is used to complex, dynamic and fuzzy state, which processing the problem as an integral whole, and treat problems from different standpoints, it is analyzed the birth to more than one direction nonlinear correlation, and it makes a decision finally. That is to say, integrated thinking is to pay attention to the cultivation of learners' high order.

C. the value orientation:

The emphasis of our project management professional is to master all discipline theory knowledge, students lack of necessary professional practice ability or practice ability, namely there are emphatically do know light value orientation. The students learned a lot of good theory, but they cannot solve problems in this kind of serious theoretical tendency. By the classification of the problem from the perspective, we Mean to our education which pays more attention to clearly define the problem, good structure to the solution of the problem; The attention and training are not enough in adaptive solution of carrier structure problems, and how to unclear definition problem is transformed into clearly define the problem, how to build their own model. Integrated thinking is emphasized the cultivation of practice ability very, that is, it trains the 
student to solve practical problems through the special theory research and the real business case analysis and commercial practice training. Integrated thinking is to attend to solve the clear definition and carrier structure problem, the model integration to the choice of conflict model. We will get a better solution through supporting the existing model information carding and creating a new pattern.

\section{D. the teaching organization form and method}

The teaching organization form is basically taught in Chinese teaching, that is 'injection" or "cramming' class teaching form, which forms the relatively obvious "simplification" features, but autonomous, teaching and research type teaching are relatively rare. The integration thinking is the diversity of teaching organization forms and methods, it's the teaching is not the single to teach the class form, mainly to diversified methods of embedded individual form, group form and class form, which pays attention to the independent type and teaching, and deepens and the develops of learners' higher-order thinking ability, utmost ground rich learning resources, time and space, the way, and the experience, then improve the teaching effect. Case teaching as a teaching effective method is to further improve and widely used in integrated thinking training to project management professional, which is emphasized the enterprise the current focus on topics into the classroom. Case teaching is used in the case through the narrative description reproduce a manager or a management organization had faced the real situation, and it provides many kinds of facts and data of decision needs. The part of real life is putted into the classroom in case teaching, which let the student to analyze and solve problems in the decision maker's status. In case discussion, students are required to take the decision-maker responsibility to identify and define problems, put forward the goal and decision criterion, and find out all kinds of feasible scheme, then make judgment, decision making and the implementation of the scheme. Through this learning process, the student's ability to analyze and solve problems are improved, they can put the application of the theory by learning in management practice.

$E$. the study on the way:

The mainstream mechanical accept or force-feeding of accepting study is still learning style in our country university .Integrated thinking is improved mechanical accept or force-feeding acceptance study, but is adopted diverse orientation, such as creative learning and inquiry learning, collaborative learning and independent learning, its core value orientation is propose creative learning. Integrated thinking is integrated on the different course content and different teaching link, it emphasizes the contact enterprise practice, and it requires us curriculum and teaching organization around the business activities of enterprises. Integration thinking pays more attention to strengthen the students' practical working ability through various channels and ways, the question as the guidance of learning, cooperative learning and team learning are widely adopted.

\section{III.THE SCIENTIFIC RESEARCH WORK}

\section{A.Education system}

Because 'GuanShuXing' mode is basically form in our country's engineering management professional education system, so trained researchers are not good at question and puts forward the question ,but used to reference even copy others' research achievements, they are lack of independent thinking and innovation of the fine God. The same, because of scientific research work enthusiasm and initiative shortage, many researchers subject only to have a little modification and supplement theory, they lack of this professional as exploration. Therefore, the scientific research work is not prone to breakthrough, also no easy to make outstanding accomplishments academic masters. The basic idea of integration thinking is innovation, hew out creative new ideas. Therefore, the integration thinking training is beneficial to the cultivation of the innovative spirit.

\section{B. University organizational structure setting}

China's current university organizational structure is separated into many institutions according to the subject and even professional, they carry out teaching research activities by professional as the basic unit. This kind of organization structure, which is artificially splitted the relationship between the subject and hinded the professional caliber development, it cannot strengthen cooperation between the subjects and development of interdisciplinary subject and enhance university strain capacity. For instance, project management professional, which pays attention to the main course of civil engineering course, but it is less for accounting, computer, and management science curriculum. The contemporary scientific research cannot be finished by a person, a laboratory or a subject strength, many problems of comprehensive multidisciplinary are solved by cooperation. Integrated thinking theory involves psychology, behavior and decision science, management science, economics, computer science and other fields, and the integration thinking training is positive promote role on interdisciplinary and interdisciplinary research work and composite research talents.

\section{Scientific research management concept}

Scientific research management concept of the project management professional does not get rid of the influence of the planned economy, 'weight management, light service', 'heavy achievement, light conversion', scientific research achievements conversion rate is low, people are weak awareness of market. Integrated thinking's emphasizes to be solute the problem of engineering practice, and it is close to the real life and market environment, so it is reference significance to scientific research management. D. Scientific research personnel's heart

Many researchers usually exist 'get rich quick' psychology now, or there is a certain purpose to do scientific research, which is unfavorable to the deepening of scientific research work. But the important requirement of the operation of the integrated thinking is 'give yourself 
enough time to explore', which reflects the time and energy is tremendous, so it can more effectively change the 'get rich quick' phenomenon.

\section{IV.CONCLUSION}

The integration thinking is a new mode of thinking and concept, its thought and basic principle are accepted by more and more people. This paper briefly introduced the integrated thinking, then it focus on the integration of higher education thought of teaching and scientific research important guiding significance. In short, the integration thinking is adapted to the social comprehensive open, the world economic integration, information and the trend of the market demands, and it is strong practical significance to the higher education teaching and scientific research for the further development

\section{ACKNOWLEDGEMENT}

This work was supported by teaching reform project of Central South University of Forestry \& Technology (2012)

\section{REFERENCE MATERIAL}

[1] Moldoveanu,M. Thinking Strategically about Thinking Strategically:The Computational Structure and Dynamics of Managerial Problem Selection and Formulation[J] .Strategic Management Journal, 2009, 30 :737-763.

[2] Martin,R.The Opposable Mind:Winning Through Integrative Thinking[M].Boston:Harvard Busuness Press,2009.

[3]Moldoveanu,M.and Martin,R.Dia-minds:Decoding the Mental Habits of successful Thinkers[M].Toronto:University of Toronto Press,2009.

[4] Moldoveanu,M.A Science Tood Cruel for words:Understanding by Interrening[M].Toronto:University of Toronto Press,2009.

[5] The shantou university to attend "the university of Toronto, Canada ROM waterman training program integration thinking" [J]. Journal of shantou university (humanities and social science edition), 2009,(06) 